CRÍTICA DE LIBROS 



\section{ENRIQUE MARTÍN CRIADO Y CARLOS PRIETO (coords.) (2015): Conflictos por el tiempo. Poder, relación salarial y relaciones de género; Universidad Complutense-Centro de Investigaciones Socio- lógicas, Madrid.}

Conflictos por el tiempo es una colección de estudios empíricos donde se remarca que el trabajo ya no es lo que era y que eso está dando un vuelco a nuestras vidas. Sobre todo, porque hacen casi imposible la articulación de tiempos $\mathrm{y}$, por lo tanto, las convivencias. Tal vez, la vivencia a secas, pues ¿qué vivencia queda sin la convivencia? Unas transformaciones que, por lo tanto, nos afectan a todos. Pero, como suele ocurrir, más a unos que a otros. Más a los que ya parten de una situación de subordinación, de estar bajo el dominio, como es el caso de las mujeres.

Estudios fundamentados en observaciones empíricas y aunque varían las prácticas de investigación social concretas referidas en cada uno de ellos, domina la perspectiva cualitativa y, sobre todo, la lógica de los estudios de casos, centrados en sectores de asalariados. Ello permite una sólida fundamentación de los hilos argumentales desde una gran viveza, que hace que el lector se implique empáticamente en la mayor parte de los capítulos. Ello no es obstáculo para que se utilicen ciertas referencias cuantitativas cuando se abordan las transformaciones, como en el caso del sector de los grandes almacenes, desarrollado por Pilar Carvajal y Enrique Martín.

Más que los números, se nos quedan impresas imágenes. Cuando se hace el retrato de las consecuencias de la externalización en el campo del mantenimiento de las centrales nucleares, donde la descripción lleva a la muerte por acumulación de radiación o por accidente de tráfico por traslados urgentes tras largas horas de trabajo. Si el relato centrado de Thébaud-Mony ubicado en las centrales nucleares es emocionante, pues el tiempo de contrato deviene en tiempo de muerte, no le está a la zaga el de Héléne Bretin sobre esas mujeres que trabajan limpiando nuestras oficinas cuando los demás no estamos en ella. Parias del tiempo y, por lo tanto, parias de la sociedad.

Los sectores abordados son pertinentes: financiero, enfermería, limpieza de oficinas, trabajadores "externos" de centrales nucleares, grandes almacenes o superficies comerciales, puesto que en estos se establecen especiales gestiones del tiempo y, tal vez lo que sea más importante desde una perspectiva sociológica, donde se establecen nuevas 
formas o modelos de gestión del tiempo, destinados, en la mayor parte de los casos, a una mayor intensificación de la mano de obra; pero, sobre todo, porque son gestiones del tiempo laboral, de trabajo reproductivo, que difícilmente se articulan de los otros tiempos, cuyo destino es devorarlos, como en el cuadro de Goya, de la Quinta del Sordo, Saturno se come a sus hijos. Seguramente hay otros sectores igualmente interesantes y espero que el equipo de autores formando vaya abordándolos en sus futuros trabajos de campo. Estoy pensando en sectores como el de los "call center", al que, por cierto, hace referencia Owen Jones en CAVS como el nuevo modelo de la gestión de la mano de obra, incluso los representa como la "nueva minería". Los mineros tradicionales barrenaban algo tan sólido como la roca para obtener el mineral buscado. Los mineros actuales de los call center barrenan algo tan líquido como la comunicación para buscar clientes. Los primeros volvían a casa con su dosis de silicosis. Los segundos se quedan en casa, pues muchos call center se realizan desde las casas de los propios teleoperadores, acumulando dosis de rechazo social y estrés llamada tras llamada. La disponibilidad aquí es absoluta, pues todo el tiempo y parte del espacio propio se pone a disponibilidad de los fines de la empresa.

Tal vez hubiera sido interesante apuntar qué peso tienen los distintos sectores abordados en el conjunto del asalariado español, belga o francés, para tomar cierta perspectiva o, a lo mejor no, y es preferible no tomar perspectiva. El caso es que queda la duda de cuál es el peso de estos "parias del tiempo". Por otro lado, nos lleva a pensar también en los "privilegiados" del tiempo asalariado, entendiendo como privilegio los derechos ganados y, sobre todo, resistidos a lo largo del tiempo. Creo que no sólo es importante apuntar hacia los derechos que se pierden sino, también, hacia los derechos que se tienen, para tener conciencia de ellos y no perderlos. Aquí me refiero a la jornada intensiva a lo largo del año. Se nos quiere hacer ver que el horario de 9 a 5 es el mejor; pero más para quebrar la resistencia de la jornada intensiva, que para que los horarios de 9 a 9, con parada intermedia, se reduzcan.

Es verdad que, para tales resistencias $\mathrm{y}$, sobre todo, para desarrollar políticas alternativas y destinadas al bienestar de la población en la gestión del tiempo, hacen falta marcos políticos dispuestos a ello. Pero, también, resistencia interna desde las propias empresas y sectores. Voy a volver a la experiencia propia. Cuando se entró en la $\mathrm{CE}$, allá por 1986, se planteó por parte de la patronal bancaria la necesidad del cambio de horarios comerciales... para ajustarnos a los horarios europeos. No lo consiguieron. ¿Se ha hundido la banca por esto? No. Si se ha hundido es por la corrupta gestión llevada a cabo especialmente en las entidades que eran públicas. Algo de lo que, por cierto, eran conscientes sus empleados desde hace mucho tiempo, igual que lo eran partidos políticos, asociaciones empresariales y sindicatos y que, sin embargo, nadie denunció. Pero ésta es otra historia, que nadie denunció.

En la jornada intensiva, tenemos uno de los mejores horarios laborales, en términos comparativos, que ahora disfruta alrededor de un $22 \%$ de los asalariados; preferentemente en las administraciones públicas, en banca y, cada vez en menor medida, en seguros. Ello me ha llevado a preguntarme cuál es el grado de satisfacción de los asalariados españoles con sus horarios laborales.

- El 85\% no desea cambiar de horario laboral (EPA, 2T 2016).

- Menos que el 96,7\% del 3T de 2002; pero más que el 79,4\% del 2T de 2013.

Dada la información cualitativa que se 
recoge en el libro, se invita a la reflexión sobre qué se quiere decir con "no desea cambiar de horario laboral". Tal vez:.

- ¿No desear cambiar de trabajo, no poner en riesgo el empleo con un cambio, cualquiera que sea?

- ¿La percepción de que cualquier cambio puede ser a peor, dado el contexto?.

- ¿Hay una gran mayoría de asalariados que están satisfechos con su horario?

Se presentan los horarios comerciales por Carvajal y Martín Criado, la adaptación a los horarios de los clientes, como un horario que hay que resolver ajustando los horarios de los trabajadores de una manera que les impide planificar sus días y sus vidas. Tal vez el problema es que se quiere atrapar todo el horario con el mismo número de trabajadores e incluso con menos, y se traslada sobre estos todos los ajustes. Se quiere tener abierto el comercio desde las 9 de la mañana a las 10 de la noche, incluyendo los días festivos. Si los clientes están los sábados y los domingos, pues a lo mejor no están los martes o miércoles por la mañana o los jueves por la tarde. ¡Cierre en algún momento! Es como si, en los restaurantes españoles que no son de fast food, se dieran comidas a las 11 o las 12 del mediodía o a las 5 o las 6 de la tarde, de manera que todo su personal tuviera que estar disponible en esos horarios, no sea que a alguien le entren ganas de comer a esas horas y se le ocurra ir a la competencia.

En cualquier caso, quiero resaltar que la lucha por el tiempo es una lucha política, que seguramente merece la pena lucharla. En el capítulo 2 se dice que las patronales de las grandes superficies comerciales se "aprovechan" de la legislación. Y es verdad; pero ¿hasta qué punto tal legislación no ha estado impulsada por ellos y recogida por los distintos gobiernos? ¿Qué justificación ha dado el gobierno para facilitar los cambios de turnos a los trabajadores o para "complementar" los horarios de tiempo parcial? Me parece que ninguna. Desde el título, en la obra hay una perspectiva de género. Imprescindible cuando el objetivo es poner en evidencia los conflictos sobre el tiempo y cuando el tiempo de trabajo se estira y estira hasta casi el infinito, como apunta el artículo de Esteban Martínez sobre la disponibilidad temporal de los asalariados. Sin embargo, se atiende menos a una división que también recorre el libro, aun cuando de una manera menos evidente, como secundaria, y que se está mostrando relevante en este campo de los conflictos temporales entre categorías, como en otros campos, como es la edad. Ya se apuntaba en un libro al que, no sé bien porqué, me ha recordado éste, como es el de La Miseria del Mundo, coordinado por Bourdieu. Hay que tener en cuenta que:

- Son los que en mayor medida sufren los nuevos horarios "atípicos" del sector productivo, como se apunta en el libro en sectores como los grandes almacenes, la enfermería, sector financiero o los de mantenimiento de centrales nucleares. Son los más jóvenes, como en el caso de la enfermería, los que entran en determinados servicios, los "más penosos" (p.123). Son los más jóvenes los que limpian los peores focos de radioactividad de las centrales nucleares, sustituyendo a los más adultos, ya absolutamente contaminados de radioactividad.

- Son los más vulnerables al doble juego de la precarización y las expectativas, dispuestos a asumir muy malas condiciones cuando han interiorizado que es la única manera de, y aquí retomo el lenguaje bíblico habitualmente utilizado: "ganarse un futuro", "ser recompensados después con el esfuerzo".

- Son los becarios y en prácticas que, en este país, en la mayor parte de las empresas no son pagados 
monetariamente, en pos de unas líneas de experiencia en el currículum. Son los que soportan los peores horarios y los que, a la vez, sostienen el 24x7x365 de muchas empresas. Por ejemplo, miren las redacciones de los periódicos en verano o por la noche: un jefe y el resto jóvenes en prácticas profesionales, cobrando muy poco o incluso pagando por trabajar.

Aquí, de forma pertinente, se asume la perspectiva de género, y el interés por políticas que pongan la igualdad material y temporal entre los sexos en su centro. Políticas públicas y políticas domésticas o micropolíticas. Así, Sara Moreno nos pone sobre la pista de interesantes apuntes. De cómo, en las generaciones relativamente jóvenes, se asume en abstracto, como norma, la igualdad en la división del trabajo doméstico y cómo, en lo concreto, apenas se lleva a cabo. Resalta así la distancia entre lo formalmente normativo y la práctica ampliamente aceptada. Entre el deber ser y el $e$. Entre lo considerado justo y el poder. En sociología, al menos desde la sociología funcionalista, nos habían enseñado que, cuando se daba tal gap, era una especie de desequilibrio momentáneo que terminaría solucionándose, de manera que el "deber ser" se acerque al "es", o el "es" al "deber ser". Pues aquí no parece que haya acercamiento, como muestran distintas fuentes estadísticas y las evidencias cotidianas. Tal vez por ello y de una manera maravillosamente práctica, Moreno nos da un consejo: "no asumir los costes cotidianos de la tensión al inicio de la convivencia tiene un precio cuando crece el volumen de trabajo doméstico con la responsabilidad del cuidado de los hijos".

Más allá de sus sabios consejos, el capítulo de Sara Moreno está destinado a desempeñar un papel clave en el libro, en cuanto, al tratar los conflictos de género alrededor de la distribución del tiempo, en clave generacional, tomando dos generaciones, que sospecho que es la de sus padres y la de ella.

La disponibilidad y, su correlato, la extensión del número de horas trabajadas sin remuneración económica, ni de días, y sólo dejada a una potencial y arbitraria remuneración simbólica, entre los estratos asalariados no ejecutivos mejor colocados, genera una especie de nueva economía en negro complementaria de la otra economía en negro. Igualmente que hay una economía en negro monetaria, hay una economía temporal en negro que hemos "naturalizado", ya que esto no se hacía antes, cuando trabajaba en la banca. Es una economía que se genera por esas horas que se hacen sin cambiar por dinero u otras horas, que se hacen:

a) Por imposición empresarial y miedo al despido.

b) Por expectativas, en los cuadros.

La disponibilidad abordada por Esteban Martínez abre el campo de lo difuso, de las normas latentes, en las relaciones laborales, frente a las relaciones regladas. Se imponen las normas no escritas, las negociaciones individuales, las horas sin registrar. Un mercado laboral negro dentro del mercado laboral blanco. Tal vez el más blanco. En el mejor de los casos, se blanquea la disponibilidad y la acumulación de horas negras con la movilidad en la empresa. Eso, en el mejor de los casos. Lo más extendido, es el castigo si no se acepta tal disponibilidad.

Otros sectores, otras categorías sociales, nuevos debates y, seguramente, nuevas propuestas en la gestión del tiempo y la necesidad de dar alternativa a estos procesos llevan a pensar que la red de investigadores que está detrás de este libro no ha hecho sino empezar y que, tras el éxito del primero, vendrán más. Se abordan procesos de largo alcance, que, además, parece que no van en el mejor de los sentidos:

- Precariedad, subcontratación,

- La descolectivización de la negociación, dejando sin fundamento 
buena parte del Derecho Laboral, y el aumento de la negociación individual, que adquiere las características de una negociación mercantil.

- La proyección de estos problemas en nuestras vidas cotidianas, en nuestro malestar. Yendo incluso más allá de los conflictos del tiempo. El capítulo dedicado a la falta de seguimiento en las centrales nucleares apunta a los problemas de seguridad que comportan la externalización de las tareas. Algo que, sin demasiada imaginación, puede extrapolarse a sectores como el transporte aéreo. Así, mientras nos hacen pasar por disciplinados controles a los pasajeros, tal vez los externalizados controles sobre las condiciones de los aparatos y los trabajadores, como los pilotos, no son tan disciplinados.

- Las respuestas prácticas de la compaginación casi imposibles de horarios, como la que muestra Paul Bouffartigue entre las enfermeras, son parches de difícil mantenimiento.

- Un proceso de intensificación de la explotación del tiempo que tiene sus víctimas directas, los propios trabajadores, en cuanto trabajadores y en cuanto cuidadores. Especialmente cuidadoras. Es aquí donde Torns, Moreno, Borrás y Recio ponen la clave del futuro: la crisis de los cuidados.

Conflictos por el tiempo es primeramente un libro comprometido con el bienestar de los ciudadanos, con el bienestar en su vida cotidiana. En definitiva, con la felicidad como meta.

Una felicidad amenazada, porque las cosas pueden ir a peor en los conflictos derivados de las injusticias temporales. Los ajustes horarios en el campo del tiempo de trabajo tienden a ser peores, subyaciendo una especie de demanda de disponibilidad infinita de la mano de obra. Cuestión que, claramente choca con cualquier horizonte de felicidad y de la necesaria disponibilidad horaria para otras actividades. Es aquí donde, al final del libro, se apunta la otra gran amenaza: la crisis de los cuidados, articulándose con la crisis del empleo. La devaluación continua del segundo conduce a la devaluación continua de los cuidados. Los diarios españoles y británicos (The Guardian) ya han empezado a hacerse eco de personas mayores que mueren de frío por no poder pagar la factura del suministro correspondiente, o quemados, al intentar sustituir por viejos métodos de combustión la ausencia de tales suministros.

Frente al pesimismo de la razón, el principio de esperanza. Mejor dicho, a esperanzas apoyadas en la razón y, lo que tal vez sea más importante, la experiencia. Hay propuestas muy fundamentadas, se hace especial referencia a las experiencias italianas, que tal vez merezca la pena recuperar. Sobre todo, cuando ya se es consciente de algunos errores de su concepción.

Como debilidades para la acción política, se apuntan las de los movimientos sociales y, en especial, de los sindicatos de clase. Así como la extensión de una masa asalariada adulta en desempleo o con salarios muy bajos, y, sobre todo, muy vulnerable y dispuesta a aceptar peores condiciones laborales.

Las amenazas están ahí. Por ello, el interés que tienen libros como éste, que nos aportan conciencia sobre tales amenazas y, así, nos dan la oportunidad de ser más fuertes. Muchas gracias por el libro y enhorabuena.

Conflictos por el tiempo es un libro interesante, importante, imprescindible e incesante, que, sobre todo, respira el aire de nuestro tiempo, de lo que vemos a nuestro alrededor si queremos mirar. Un libro que invita a mirar y, como no deja impávido, a actuar. 
